Revista do CESP, Belo Horizonte, v.36, n.56, p. 31-42, 2016

\title{
Zalina Rolim e Helena Morley: duas escritoras-educadoras
}

\section{Zalina Rolim and Helena Morley: two women writers-educators}

\author{
Maria Lúcia Dal Farra \\ Universidade Federal de Sergipe, Aracaju, Sergipe / Brasil \\ mldalfarra@gmail.com
}

Resumo: Este artigo compara duas escritoras-educadoras brasileiras - Zalina Rolim e Helena Morley - que escreveram e publicaram no final do século XIX, uma paulista e outra mineira, uma poetisa e outra narradora, ambas preocupadas com a educação infanto-juvenil e ambas revelando nas suas obras literárias, cada qual a seu modo, aspectos relevantes da burguesia brasileira à sua época e da condição feminina no seio da família burguesa.

Palavras-chave: Zalina Rolim, Helena Morley, infância, patriarcalismo, condição feminina.

Abstract: This article compares two Brazilian writers-educators women - Zalina Rolim and Helena Morley - who wrote and published at the end of the 19th century, one from São Paulo and one from Minas Gerais, one poetess and another narrator, both concerned with the education of children and adolescents, both revealing, in their literary works, each in its own way, relevant aspects of the Brazilian bourgeoisie of their time and the feminine condition within the bourgeois family.

Keywords: Zalina Rolim, Helena Morley, childhood, patriarchy, female condition. 
Recebido em 30 de setembro de 2016.

Aprovado em 30 de novembro de 2016

À minha querida Lélia

Trago uma aproximação entre duas escritoras, que é uma forma de pensar os laços entre literatura e ensino - ao mesmo tempo uma maneira de honrar o trajeto tão benemérito de artista, ensaísta e educadora da minha querida amiga Lélia Parreira Duarte. Enfoco, pois, duas mulheres brasileiras nascidas no século XIX, que articulam, implicitamente, alguns liames entre si. Trata-se de Maria Zalina Rolim Xavier de Toledo, nascida em Botucatu (minha terra natal), Estado de São Paulo, a 20 de julho de 1867, e falecida na cidade de São Paulo, em 21 de junho de 1961. E de Alice Dayrell Caldeira Brant, nascida em Diamantina, Minas Gerais (estado natal de Lélia, que é oriunda de Formiga), em 28 de agosto de 1880, e falecida no Rio de Janeiro em 22 de junho de 1970.

Situo-as em regime de contiguidade porque, uma paulista e outra mineira, uma poetisa e outra narradora, produzem suas obras mais ou menos na mesma altura, em finais do mesmo século, e sustentam um dote comum - o de educadoras. Além disso, pertencem as duas a um estrato social semelhante. Zalina Rolim, filha de juiz, é mulher de promotor de família eminente da região, os Xavier de Toledo, cujo nome, como se sabe, faz parte do patrimônio geográfico do centro da cidade de São Paulo. Alice Dayrell Caldeira Brant (dita Helena Morley, pseudônimo através do qual será conhecida como autora), muito embora tenha tido uma infância modesta, descende, do lado paterno, de ingleses de antiga nobreza. Migrados para o Brasil no princípio do século XIX, ela se casou com o primo-irmão diplomata (cujo sobrenome - Caldeira Brant - diz respeito à linhagem dos Barões de Barbacena), que foi deputado, Secretário de Estado, Presidente do Banco do Brasil, e, mais tarde, exilado político na Europa e na Argentina. Helena Morley é sogra de Abgar Renault, importante político e Secretário de Estado, destacado poeta e tradutor - o que dá sinal do ambiente intelectual em sua casa do Rio de Janeiro, um palacete defronte à Lagoa Rodrigo de Freitas.

O romance de Morley - aliás, sua única obra publicada: Minha vida de menina - tem como subtítulo Cadernos de uma menina 
provinciana nos fins do século XIX e aponta, logo na nota inicial da autora, o desígnio de passar para as suas "netas" e para "as meninas" as suas experiências de escrita e de vida, a fim de que possam se aperceber da diferença entre um e outro tempo. Refere-se ela à época de feitura dessas páginas, redigidas entre 1893 e 1895, e ao tempo atual, 1942, data da primeira edição da sua obra. ${ }^{1}$

Zalina, por sua vez, está estreitamente ligada à criação do "Jardim de Infância da Escola Normal de São Paulo", que ocorre em 1896, pioneira na educação no Brasil, e o seu livro especialmente composto para a educação infantil, O livro das crianças, vem à luz em 1897. A importância desta botucatuense como educadora, a sua incisiva atuação como uma das primeiras produtoras de textos para crianças, fica anotada no fato de que Zalina recebe, em 1954, uma homenagem do governo brasileiro, quando é então dignificada com a insígnia de "Mestra do IV Centenário de São Paulo". ${ }^{2}$

Por seu lado, a obra de Morley imanta mulheres destacadas: para o caso, importantes escritoras da época, Rachel de Queiroz, sua leitora e admiradora (que ao romance regressará por vezes), e Elizabeth Bishop, poetisa americana que, em 1957, a traduz e a prefacia em língua inglesa, publicando-a em Nova Iorque e em Londres. Para além destas, há no elenco de suas importantes leitoras a pesquisadora e estudiosa brasileira, minha saudosa amiga Marlyse Meyer, que, mais tarde, em 1960, verte-o para o francês, feição através da qual George Bernanos irá lê-lo e apreciá-lo sobremaneira, visto que o apresenta - o que diz muito da sua aceitação e dos leitores que angariou desde então. E nomeio apenas alguns dos inúmeros admiradores que Morley foi repertoriando ao longo do tempo, como Guimarães Rosa, Gilberto Freyre, Carlos Drummond de Andrade, José J. Veiga, Rubem Braga, Alexandre Eulálio e, mais recentemente, Roberto Schwarz. O romance também alcançou uma primeira filmagem em 1969 (sob a direção de David Neves, no longa intitulado "Memória de Helena"), e regressou à grande tela em 2004, com

\footnotetext{
${ }^{1}$ A propósito, em 1997, Roberto Schwartz publicou um excelente ensaio sobre o livro, em Duas Meninas. São Paulo: Companhia das Letras. Utilizo, para citação, a 8a edição da Livraria José Olympio Editora, a de 1966 (Rio de Janeiro).

${ }^{2}$ Tal pesquisa só foi possível graças à edição organizada e publicada por Maria Amélia Blasi de Toledo Piza, Zalina Rolim, poetisa e educadora (Botucatu: Ottoni Editora, 2008). Esta autora é também uma insigne botucatuense, escritora e musicista.
} 
o título "Vida de Menina", sob a direção de Helena Sontang. O roteiro desta película diverge, em todo o caso, dos expedientes do romance, mas o temperamento da personagem principal, agitado e inconformista por excelência, se mantém absolutamente fiel assim como fica preservado o contexto da época, enriquecido por uma belíssima fotografia muito apropriada ao tratamento do tema, que parece de fato emoldurar, senão encarnar os relatos do diário de Helena.

A obra de Zalina Rolim (e já agora refiro o montante dos seus textos poéticos) não fica atrás no reconhecimento que ganha desde 1887. São seus leitores e comentadores Ezequiel Freire, Narcisa Amália, Gastão Bousquet, Olavo Bilac, Adelina Lopes Vieira, Machado de Assis, Arthur Azevedo, Pinheiro Chagas, João Ribeiro, Araripe Júnior, João Köpke, Vicente de Carvalho, Domingos da Silva Carvalho, só para citar aqueles mais proeminentes.

Uma outra questão poderia ser aventada aqui, quando trato de justapor estas duas escritoras, e não custa tangenciá-la ao menos. Teria sido de fato escrita a obra de Morley na data que ela lhe confere, ou seja, em 1893, 1894 e 1895, ou tratar-se-ia de uma refundição mais recente, que modificou os cadernos segundo os critérios de uma escola literária mais contemporânea? Esta dúvida, que já ocupou espíritos interessados, não modifica, entretanto, a evidência a que chegou Guimarães Rosa. Porque se a obra fosse deveras uma "impostura literária", escrita pela autora madura, estaríamos diante de um "caso" ainda mais extraordinário, visto que não há, que se saiba, em nenhuma outra literatura, exemplo tão pujante de tão literal reconstrução da infância. ${ }^{3}$

Pois bem. A título de introduzir o motivo com que me deparo, adianto que Minha vida de menina desenvolve duas imagens femininas díspares: a dupla Helena e Luisinha, as inseparáveis irmãs. De um lado, a narradora-menina, que acompanhamos dos 13 aos 15 anos, é a mais velha das duas, a segunda de uma família de quatro filhos, garota travessa e inteligente, observadora e crítica, muito franca e dona do seu nariz. Amiga do dispêndio físico e avessa ao imobilismo, extremamente ativa, Helena não deixa passar coisa alguma: tudo a sua escrita absorve; rebelde e impaciente como ela mesma, "incapaz de obedecer". Nada

\footnotetext{
${ }^{3}$ Alexandre Eulálio, meu querido e saudoso amigo, na apresentação da edição que utilizo, narra esta especulação de Guimarães Rosa, em conversa com ele. Cf. "Livro que nasceu clássico", Opus cit., p. X-XIV.
} 
permanece ileso diante do seu crivo penetrante e personalíssimo, da sua curiosidade e das especulações que, sobre qualquer nadinha, é capaz de tecer e questionar, inscrevendo-as no companheiro caderno que, como uma sombra, a acompanha por todos os deslocamentos, lugar íntimo onde ela registra cada passo que dá na sua deambulação sem tréguas por Diamantina e seus arredores.

Helena percorre, assim expedita, os espaços abertos e privados da sua cidade acidentada, subindo e descendo ladeiras, procurando o que fazer e o que ver e sobre o que indagar. Visita, na sua rotina peripatética, as casas dos parentes e dos vizinhos, as chácaras e sítios de amigos e familiares. Frequenta a escola e as igrejas com suas novenas, missas e procissões, participando das festas, dos brinquedos, dos jogos e das comemorações, vistoriando, com a mãe e os irmãos, os diferentes ranchos por onde a miragem da mineração (nesta altura, quase esgotada) vai movendo incertamente o seu pai. Enfim, não há canto que ela, com seu olhar luminoso e racional, não reflita e tematize - não interprete à sua medida.

Por seu turno e em movimento contrário, muito embora a seu lado, encontra-se Luisinha, a irmã cordata e "um anjo de bondade" - aquela de temperamento módico e nem um pouco ousada. Passiva e sem relevos (muito embora graciosa), calada e um tanto alheia à vivacidade e às descobertas da irmã mais velha, a sossegada Luisinha nunca sai de casa sozinha, sempre "empencada no braço de mamãe". De parecido com a mais velha, ela só tem mesmo a facécia de pouco estudiosa, a ponto de, tal como a outra, repetir de ano. Entretanto, submete-se (ao contrário de Helena) a ser interna no colégio de freiras, onde passa o tempo doente e no lamento, até que a mais velha encontre meios de convencer a família a retirá-la de lá.

Aliada às obrigações e às travessuras da irmã mais velha (que a lidera e que ocupa toda a cena familiar), Luisinha parece funcionar literariamente como um pano de fundo, como um cenário humano diante do qual é possível tornar mais enérgica e saliente a figura de Helena que, em verdade, impera - de maneira contraditória, é verdade - sobre a família e sobre a pacata vida cotidiana do antigo Arraial do Tijuco.

O cotidiano provinciano no interior de Minas, com sua lida pitoresca, preguiçosa ou repleta de pequenos trabalhos, concorrida de fofocas e casos, de ocupações domésticas, de festas religiosas, de costumes tradicionais, preconceitos, politicagem, superstições, repleta de agregados 
e de ex-escravos - são, ditos por alto, os irrequietos motivos de que se constrói o romance. Acompanhando a filtragem ideológica de Helena na apreensão deste universo, a maneira como a colegial esclarecida faz, no seu íntimo, a experiência das defasagens do mundo contemporâneo, Roberto Schwarz lê, então, a arquitetura oculta do livro - o seu traço quase utópico e a sua feição de "pastoral humorística". Porque abre-se, segundo ele, neste universo narrado, uma "brecha para um progresso de outra sorte, da ordem da reacomodação interna, de cuja humanidade e beleza o livro fala e dá prova". ${ }^{4}$ Neste verdadeiro "patrimônio cultural", como o concebe José J. Veiga, é possível ler a "história natural da família brasileira no último período do patriarcalismo escravocrata", razão por que também a obra interessa a Gilberto Freyre.

Para além da profusão de entradas que o romance nos faculta, quero refletir, para esta homenagem, apenas um ponto. A escrita de Helena é uma prática impulsionada por seu pai e, só de modo secundário, instigada por seu Professor de Português. Anoto à margem que, no referido filme, a situação vigente é a oposta da original, criando uma imagem débil e pífia para o pai de Helena, que, no romance, desempenha, inversamente, um tipo excepcional e superior a seus pares de Diamantina. Cativo do seu ofício e da sua família, Alexandre tem calete firme e digno, homem de caráter avesso a qualquer laivo de obscurantismo. Ele partilha, com os filhos, o direito de expressão e de pensamento, inculcando-lhes a necessidade do trabalho para a obtenção da alforria pessoal.

Foi o pai quem a botou, como salienta Helena, no costume de escrever quase todos os dias o que pensa e o que vê acontecer, guardando as recordações para o futuro, recolhendo nas linhas traçadas a história do tempo antigo. De maneira que, mesmo exausta dos seus afazeres diários, Helena vem ao caderno para registrar o que ouviu e o que cogitou (ou reflete à medida que escreve), as histórias ouvidas, os episódios vividos. O caderno também é depositário das suas confissões, no secreto do seu coração, para registrar algo, como num ritual de perenidade, como se ele fosse o passe para aquilo que se grava para sempre. O caderno é, ao contrário das amigas e das pessoas, de quem não se conhece senão a aparência, aquele ser digno de confiança, e Helena pode lhe segredar seus pensamentos mais privados, fatos que não tem coragem de revelar

${ }^{4}$ Cf. o referido ensaio "Outra Capitu", de Roberto Schwartz, constante do volume Duas Meninas. São Paulo: Companhia das Letras, 1997, p. 43-144. 
para ninguém, por julgar que são "falsidades" - inclusive a afeição que tem, por exemplo, pelo seu vestido de fustão que, sendo branco, pode parecer dois em vez de um...

A produção escrita de Helena, que registra incessantemente uma faxina em regra diante de tudo quanto lhe é apresentado pelo dia-a-dia, eivada de críticas - a situa, pois, em posição intelectual de igualdade com esse pai, com quem ela entra em interlocução total, o que lhe enseja até mesmo a possibilidade de tecer reparos a respeito do comportamento dele - o que parece ser um privilégio excepcional, em se tratando do sistema vigente.

Assim, a propósito das estratégias lembradas pela avó para contornar o mau gênio do marido, Helena anota:

Eu estive dizendo a vovó que eu converso com meu pai o que quero, conto tudo a ele e juro que se ele fizesse alguma coisa malfeita eu lhe falava francamente. Eu vi que vovó acha melhor assim porque ela só me disse: "É mesmo, minha filha. Os tempos estão mudados." (p. 55).

A prática de escolha do marido por parte do pai da pretendente ainda persiste no patriarcalismo comum nessa época. Mas a figura de Alexandre, monarquista num tempo republicano, é deveras especial nesse contexto paternalista. Repare-se que ele estimula os filhos ao estudo para que se tornem adultos responsáveis. "Meu pai diz que na Inglaterra não há negros e são os brancos que trabalham. Diz que um homem do povo, se for inteligente, trabalhador e direito, pode chegar a ser ministro da Rainha." (p. 66). A coexistência de dois mundos culturais divergentes, o materno - de cepa portuguesa e antigo na região, católico e tradicionalista - e o paterno - de ascendência inglesa, com ecos de uma formação protestante, liberal - podem explicar, segundo Alexandre Eulálio, a versatilidade psicológica da escrita de Helena.

Helena, que nunca tem preguiça de escrever e ainda menos de trabalhar nas suas obrigações de casa, não concebe a escrita como custosa; considera que não é coisa do outro mundo "contar as coisas com a pena". Em determinada quadra, ela narra que "Estava com a pena na mão pensando o que havia de escrever, pois há dias não acontece nada", quando passou um enterro. Então, se pergunta: "vai me dar assunto?" (p. 135). Veja-se, pois, como funciona o seu registro literário, sobre o qual, aliás, ela reflete: "Este conselho que meu pai me deu de deixar de contar 
às amigas a minha vida e os meus segredos e escrever no caderno, é na verdade bom por um lado e ruim por outro". (p. 161)

Sem desenvolver os desdobramentos acerca do feminino e do masculino existentes nesses registros, anoto a reincidência, durante a narrativa, de uma reflexão, da parte de Helena que, a meu ver, se comunica com essa decisão de tudo anotar. É a escrita que lhe dá a dimensão de desejar ter "nascido homem", muito embora, em certas horas, preferisse ser mulher. Eis, por exemplo, um indício desses: "Se eu soubesse escrever poderia até mesmo escrever um livro grande, tão compridos têm sido os dias agora para mim. Mamãe diz que eu merecia este castigo para não querer mais virar menino homem." (p. 88)

A escrita, que lhe confere maior importância ainda aos olhos da avó materna (que lhe solicita, inclusive, a leitura das redações às visitas, mas não de todo à família da mãe, afeita muito mais à obtenção de efeitos econômicos mais lucrativos) é pressentida por Helena como um bem pertencente a uma esfera que lhe é estranha, a um poder outro, do qual ela assim se apropria ou do qual é acusada de apropriar-se por esse meio. Aqui, portanto, a apologia do lar e da família burguesa é atravessada pela convicção da dificuldade de o feminino se mover num mundo masculino que o ultrapassa e de onde, através da escrita, pode-se vislumbrar um lugar de equiparação entre os sexos - ao menos fortuito.

Por outro lado, os poemas infantis de Zalina Rolim, que foi deveras uma das primeiras poetisas brasileiras da literatura infantil, ganharam nomeada na altura do começo do século XX, tratando, didaticamente, de questões de conhecimentos gerais, de educação, enfim, da formação burguesa da criança. A vox populi está presente em quase todos eles por meio dos ditados populares, espécies de faróis de ensinamento que os iluminam com a sua pretensa verdade. E os poemas se perfazem mais propriamente enquanto exercícios pedagógicos que, todavia, literários - muito embora sejam irrepreensíveis na sua forma (cuja medida pode ser tanto a do decassílabo quanto a da redondilha maior ou do octassílabo, ou a da variação entre quebrados e decassílabos ou de quebrados e alexandrinos) e encantem o ouvido pelo ritmo e pela sonoridade especialíssima dos versos.

Todavia, os poemas infantis de Zalina pintam (com raras exceções) uma existência fantasiosa e tranquila, versando sobre os cuidados maternais, a preguiça, o lazer, os livros, a arte, os deveres, a Pátria, os animais domésticos; sobre o lucro e sobre a honra, a vida na 
roça, as férias, o trabalho, as diferentes profissões, o medo, a amizade, o respeito aos mais velhos, a religão, a família. Como se depreende, não possuem eles a tonalidade rebelde e questionadora de Helena Morley, expondo, antes, o bom-comportamento, o coração de ouro e a bondade infantil, precisamente as virtudes passivas que encontramos na Luisinha de Minha vida de menina. O modelo feminino aqui sublinhado é, portanto, bem outro.

Cito um poema particularmente sintomático do que exponho. Com o título de "Em caminho", em quadras em redondilha maior, conhece-se, em 13 estrofes, a história de uma menina da roça, sua família, seus estudos, seu lar - por ela própria narrada enquanto vai caminhando para entregar ao pai (que está na lida, lavrando a terra) o seu jantar. Da maneira como ela conta, o mundo agrário brasileiro da altura, pelo menos o paulista, parece ser deveras um paraíso... E há também outros equívocos: em vez de regressar ao lar ao fim da tarde, é a filha que vai até o pai para levar-lhe a refeição que, ao que tudo indica, ele poderia fazer em casa.

O artificialismo que engessa a boa-disposição dos versos pode servir de parâmetro para a comparação inevitável: entre a vida provinciana narrada por Helena Morley e a vida de roça contada por Zalina Rolim - lembrando que ambas as escritoras estão interessadas na mesma finalidade, dedicadas que são à formação das crianças. Eis o poema:

Sou filha de lavradores;

Moro longe da cidade;

Amo os pássaros e as flores

E tenho oito anos de idade.

Quereis seguir-me à campina?

A tarde convida e chama,

O calor do sol declina,

E o horizonte é um panorama.

Neste samburá de vime

Levo cousa apetitosa;

Mas, ai! que ninguém se anime

A meter-lhe a mão curiosa. 
É o jantar do papaizinho;

Manjares de fino gosto;

Carne, legumes, toucinho,

Tudo fresco e bem disposto.

Papai trabalha na roça;

O dia inteiro labuta;

Tem a pele rija e grossa

E a alma afeita à luta.

Mas leal, franco, modesto

Como ele, não há no mundo:

Vive de trabalho honesto,

Cavando o solo fecundo.

Acorda ao nascer da aurora, Abre a janela de manso, E o campo e os ares explora

Da vista aguda num lanço.

Depois, nos ombros a enxada, Abraça a Mamãe, sorrindo, Beija-me a face rosada

E vai-se ao labor infindo.

Em casa também se lida

Daqui, dali, todo o instante, Que o trabalho é lei da vida

E nada tem de humilhante.

Depois do trabalho, estudo; Abro os meus livros e leio; Eles me falam de tudo $\mathrm{O}$ que eu desejo e receio.

Contam-me histórias bonitas, Falam da terra e dos ares, De vastidões infinitas,

De rios, campos e mares.

Mamãe diz que são modelos

De amigos leais e finos;

Que a gente deve atendê-los

Como os maternais ensinos. 


\author{
E agora, adeus, até breve! \\ Eis-me de novo a caminho: \\ Não esfrie o vento leve \\ O jantar do papaizinho.(pp.138-140)
}

Todavia, é bom de se notar que a mesma Zalina expõe, na aproximação entre este Livro das crianças e $O$ coração (o seu anterior livro de poemas publicado em 1893), uma cisão interna na sua poesia que, talvez, possa nos auxiliar a pensar o pendor artificial, moral e pedagógico do livro em pauta.

Há, em $O$ coração - obra composta por sonetos decassílabos ou por quadras decassílabas mais alentadas (e raramente em redondilhas maiores) - uma espécie de poética de contenção e ocultamento, repleta de eufemismos, de paradoxos, de voz surda de enfrentamento do consenso geral. Tal dicção demonstra uma interlocução interna (por vezes num vocabulário ainda parnasiano) que aponta para uma alteridade (que também se apresenta por meio de uma emissão masculina) e para uma tópica de rejeição. Os motivos, geralmente amorosos, convivem com poemas de natureza mista, digamos assim (visto que o vocabulário é ainda adulto e preciosístico), já numa clara transição para os versos pedagógicos do Livro das crianças.

Vale a pena citar um dos sonetos, intitulado "Ritornello íntimo", em que o ar de desafio amoroso transparece contra o mundo, na contramão dos poemas do referido Livro:

Eu vou falar de alguém que é minha glória,

Desse que acende o meu clarão divino;

Nem podem notas de estrangeiro hino

Vibrar-me as cordas de ouro da memória.

Ao seu sorriso músicas afino,

Traduzo em seu olhar lúcida história,

E vou cantando alegre a promissória

Canção de amor que em sonhos imagino...

Sei bem que o mundo unânime a serena, A invariável nota dos meus cantos,

Desdenhoso e cruel fere e condena; 
Sei bem tudo isso... e alegre e indiferente,

Ora em clave de riso, ora de prantos,

Meu amor cantarei eternamente. (p. 63)

Deposito provisoriamente aqui para você, querida Lélia, só o aceno para o estudo alentado que estabeleça o cotejo entre ambas as escritoras. É preciso avançar na tentativa de buscar compreender quais as imagens femininas que, sempre com o fito de educar as gerações vindouras, suas respectivas obras transitam. A prerrogativa do poder de escrita enquanto arma feminina também fica aqui esboçada, de maneira que noto apenas, por ora, que a "Luisinha" de Zalina pode, por vezes, também mostrar o perfil emblemático da irmã "Helena" - o que perfaz desde já uma grande conquista para todas nós!

Lajes Velha, 24 de agosto de 2016. 